\title{
Linking Organization Structures and Processes to Business Strategy
}

\author{
Douglas M. Cowherd and Robert H. Luchs
}

\begin{abstract}
There is currently a great need for the integration of organizational and strategic studies in order that one should support the other. This article describes the creation and development of a service designed as a data base to be used at the business unit level. Its objective is to provide a description of organizational variables, identify the effect of variables on strategy and provide a methodology consistent with objectives.
\end{abstract}

\section{Background}

Strategic Management has been defined as the process of general managers co-aligning their organizations to environmental opportunities and constraints.' Although much has been written in recent years about the desirability of creating a fit between organization and business strategy," this work remains largely theoretical ${ }^{3}$ or descriptive; ${ }^{4}$ empirical work in this area is rare. Instead two separate streams have emerged: ${ }^{5}$

is Strategic studies which focus on competitive analysis, and market environment and other external concerns. ${ }^{6}$

is Organizational studies which emphasize internal concerns such as organizational design, human resource systems and culture.?

There is a crying need to integrate the two streams of thought. Every day we read post-mortems in the business press that place the blame for failed strategy on organizational factors. Very few firms have achieved 'Strategic Management' which tailors an organization to support a business strategy.

No doubt the lack of sound theory is in part responsible for this sorry statc of affairs. With little evidence to rely on, the discussion of how to support strategy with organization often degenerates to the exchange of anecdotes and the invocation of the latest management best-seller.

Douglas Cowherd is at the University of Michigan and Robert Luchs is Senior Vice-President of the Strategic Planning Institute.

\section{Creation of the OASIS Program}

In response to this need to understand how to organize to implement business strategies, OASIS (Organization and Strategy Information Service) was launched in 1984 as a joint venture of Hay Management Consultants, The Strategic Planning Institute, and the University of Michigan. OASIS is designed to be a longitudinal data base consisting of environmental, strategic, organizational and performance data at the business unit level. The objectives of this effort are:

is To provide a comprehensive quantitative description of organizational variables.

is To identify the effect of organizational variables on strategic success.

is To provide an empirical methodology which can quickly and comprehensively check an organization for consistency with business objectives.

The first stage of the rescarch is now complete. Although the research is based on only 60 business units, and therefore not yet suitable for elaborate multivariate research, some of the more basic hypotheses regarding the relationship between strategy, organization and performance can bc tested. This has yielded interesting results, promising more insight when the data base expands permitting more elaborate research.

\section{Relevance of the PIMS Program}

The research approach and the structure of the data base is heavily influenced by the Strategic Planning Institute's PIMS Program, so it is appropriate to briefly review that program. ${ }^{8}$

The PIMS Program is probably the most extensive ongoing empirical research effort in the area of strategic planning. Its unique data base contains at least 4 years of detailed operating, environmental and competitive data on more than 3000 business 
units. These busincsses cover a broad range of industries and markets, primarily in North America and Europe. Research on these data has revealed that there are indeed 'regularities' in how competitive and environmental factors affect the behaviour and performance of a business unit." In practice, companies participating in the PIMS Program regularly access the data base and the models which derive from it as an aid to their strategic planning.

While the PIMS research efforts have explained a large proportion of the variation in return on investment, this research has not provided a complete explanation of business unit performance. By combining strategic and organizational variables in one research model, OASIS has the potential to elaboratc on the fundamental findings of the PIMS Program.

The PAR ROI model, for example, calculates the expected or 'normal' profitability for a business unit based on approximately 30 of its structural and strategic characteristics. Although the PIMS research underlying this model shows that over time business units tend to approach their 'PAR' or expected ROI, at any given time a business may have a deviation from this expected ROI. Indeed, uncovering such deviations is a major benefit of the model, since PIMS research reveals that incremental investment will generate returns that are more closely related to PAR than actual ROI. In the case of a negative deviation, the kcy issuc is how expected ROI can be attained. When a positive deviation is in evidence, a critical question is how to sustain this above-average performance. While other PIMS tools can provide some explanations for these deviations (c.g. poor price realization or high marketing and overhead costs), these cxplanations can perforce only refer to the environmental and strategic variables in the data base. However, experience suggests that the underlying causes are often in the organizational domain. For example, high levels of marketing expenditure with little benefit may well be due, in part, to an organizational structure with too many levels, a lack of a marketing-oriented culture, poor compensation schemes for the sales force or their lack of training in selling the benefits of a superior product. Research conducted by Hammermesh and White on business autonomy underscores the value of expanding the PIMS framework in this manner."

\section{The Methodology}

Comparative research on business organization can utilize different levels of analysis from small work teams to strategic groups of firms. The researchers collect data at the business unit level for a number of reasons. The primary reason for this choice of level of analysis is the nccd for a quantifiable measure of performance that is widely applicable across many different types of enterprises. One such measure, return on investment, requires an organizational entity that has control both over the income side of the equation and the investment that generates this return. Within this constraint, the greatest possible disaggregation of units is desirable, for this allows the modelling of unique strategic situations rather than the averaging of many different positions. The study of organization, however, also requires an intact systems of people who interact around the management of a discreet set of assets. This critcrion often requires a larger unit of analysis than one which might best fit the other two. So, the overlap which best fits all three criteria is the unit of analysis, a business unit which frequently is the same as that which is the focus of previous PIMS research.

The research team collected data on seven domains that characterize the business unit as shown in Figure 1. Data are collected from key informants within the business unit for each of the components in the model. In addition, the business unit's top management culture is assessed through an anonymous survey of this group.

The rescarch described below is based on data from 58 North American business units from a variety of industries. While this sample is much smaller than the PIMS data base, it is sufficiently large to test the basic hypothesis. Moreover, by utilizing the PIMS PAR ROI model as a performance measure, OASIS is able to build on the results of rescarch on a 3000 business unit data base.

The technique used in this research is to search for the relationship between various organizational factors and the performance measure deviation from expected ROI. The deviation from expected $\mathrm{ROI}$ is the difference between the ROI predicted by the PIMS PAR ROI model (the expected ROI) and actual performance. Thus, the deviation is the component of business unit performance that is not explained by the environmental and strategic factors included in the PIMS model, but is potentially understood through a relationship with the organizational components of the integrated model (note: in this sample there was a systematic five-point positive deviation from PAR ROI).

While the research cannot be considered conclusive due to the size of the sample, a highly significant relationship between organizational factors and deviation from expected ROI is cvident. This strongly argues that such factors must and can be taken into consideration when one either attempts to theoretically understand or pragmatically manage a business unit.

\section{Research Results}

Research on the data base has uncovered significant findings in each of the four organizational domains of the model. Research findings exemplifying each domain will now be examined. 


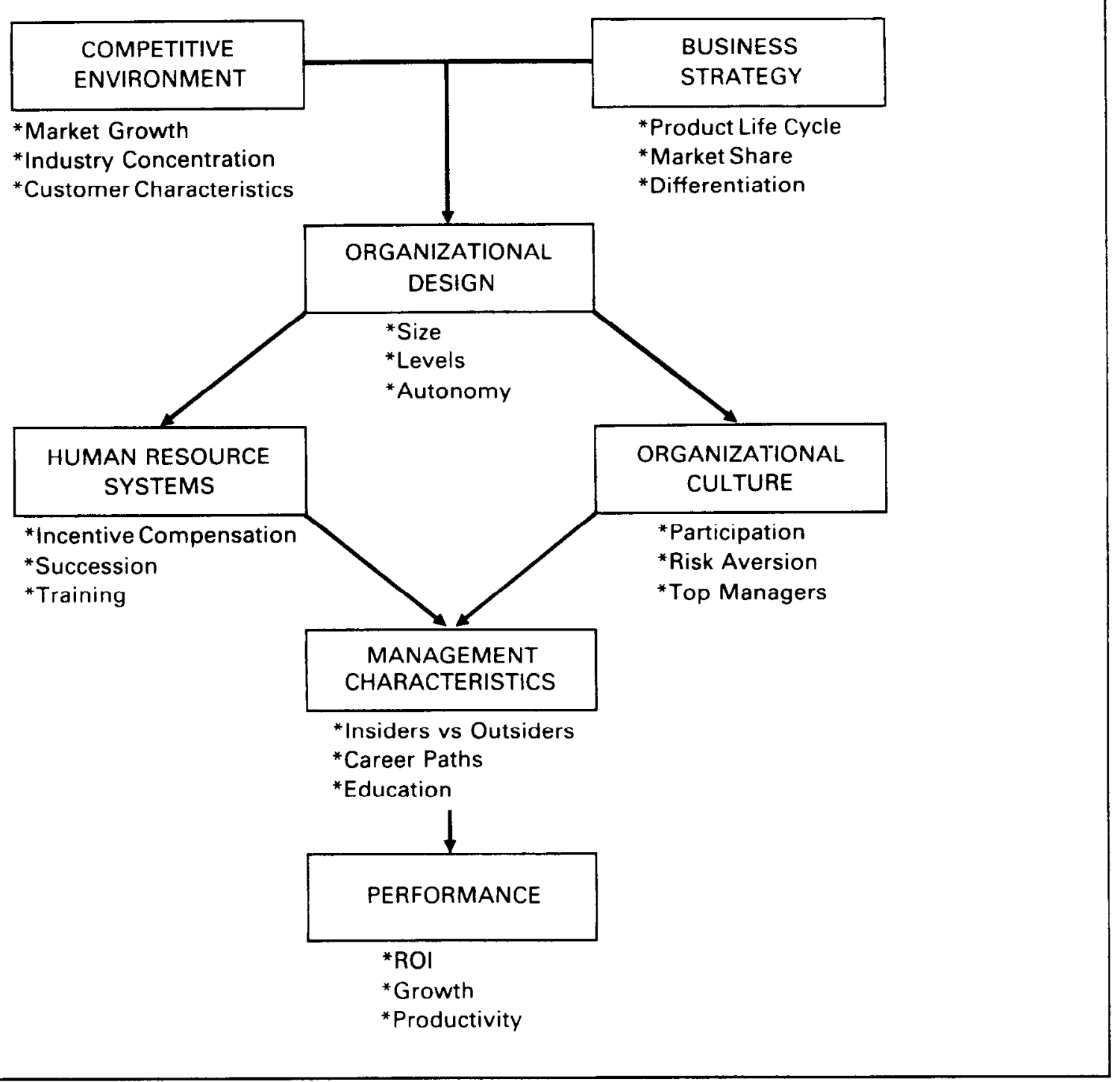

Figure 1. The rescarch model

\section{Organizational Design}

The data relating to organizational design have yielded interesting results on both the issucs of business unit size as well as levels of organizational structure.

The advocates of 'small is beautiful' and industrial economists who stress 'scale cconomies' will bc surprised that the research indicates that medium-size business units are the most profitable (sec Figure 2).*

This finding suggests that therc is an optimal mix of the scale economies enjoyed by many larger busincsses and the less burcaucratic organizational culture of smaller businesses.

Another key issue vexing business managers is the number of structural levels a business unit should

In Figures 2 and 5-8 the vertical axis is usually the deviation from expected ROI calculated on the basis of the environmental and competitive data collected on each business; the horizontal axis is the variable under examination. Averages are shown and all results are significant at the 0.05 level or above. have. The data indicate that the number of structural levels is highly correlated with the degree of a business unit's through-put. Figure 3 shows the correlation between the number of levels and total operating expenditures. This provides a guide to what is typical in terms of reporting relationships for the opcrations function of a business unit.

The key issue is the affect on business unit performance when business units are above or below their expected number of levels. The research shows that the current bias towards 'lcan and mean' structures depends on the business units through-put (see Figure 4). $\dagger$

In business units with great opcrations throughput-those in which the expected number of organizational levels is high-it is preferable to have fewer levels than is typical. However, in smaller

tNote: Although results presented here are in terms of actual ROI for simplicity of presentation, results are the same when deviation from expected ROI is used as the measure of performance. 


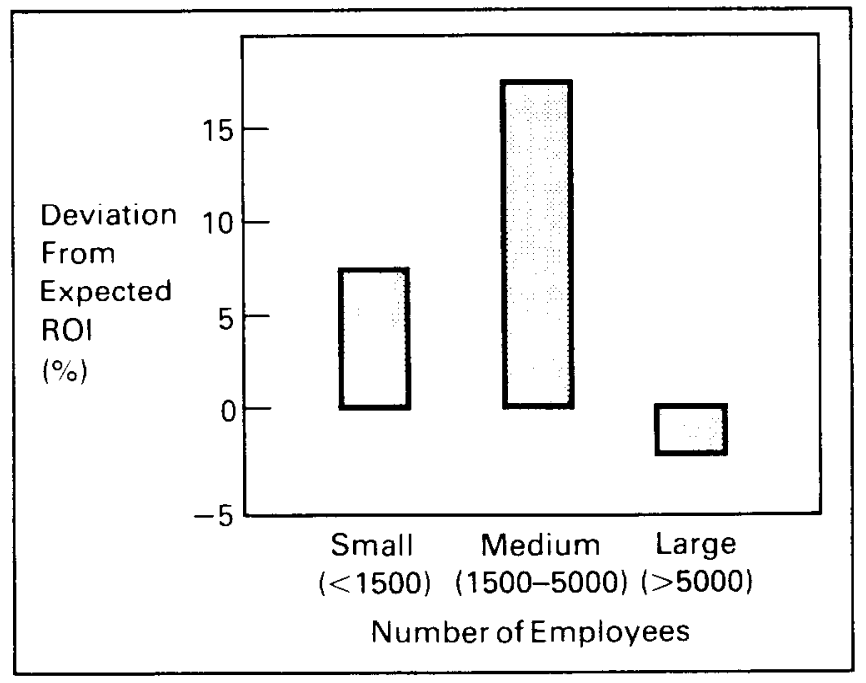

Figure 2. Medium-size businesses are the most profitable

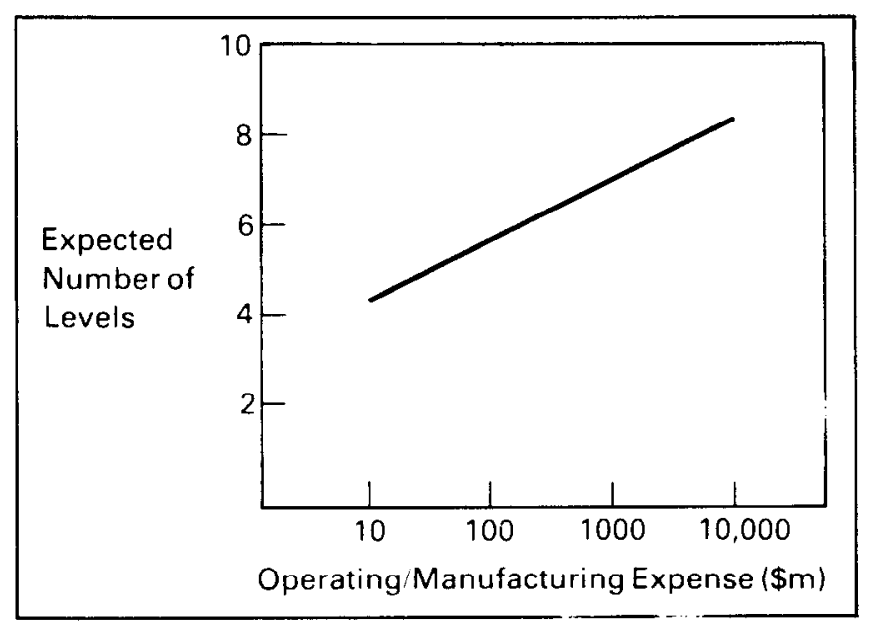

Figure 3. Calibrating expected number of levels in operations

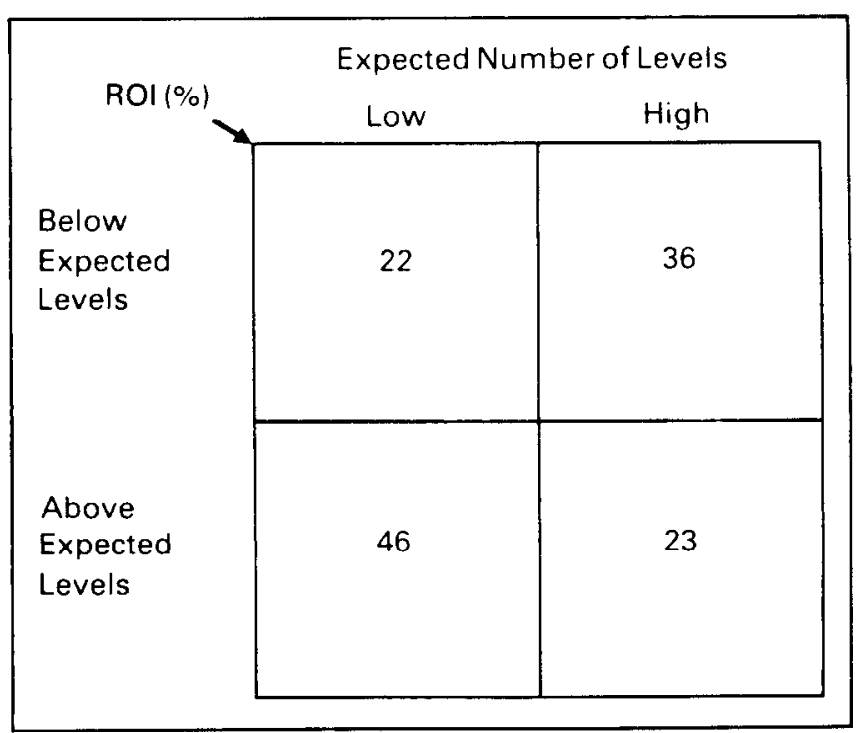

Figure 4. Profit impact of shortfall or excess number of levels in operations organizations the highest level of profitability was achieved by business units which were more heavily layered than the norm.

Onc explanation for this rather surprising finding may be that in smaller organizations there is usually less political use of organizational levels. Larger organizations tend to be older, so there has been more time for positions to have been created in order to 'kick somcone upstairs' for political purposes. In addition, the greater complexity of larger organizations creates more opportunity to hide these questionable structural accretions. In smaller organizations such practices are more obvious, and so less prevalent. More commonly, smaller organizations have another problem: excessive span of control occurs as pcople are added during growth but restructuring the organization lags behind. An 'excess' layer or two under these circumstances appears to solve more problems than are created.

\section{Human Resource Systems}

The data collected in this area included comprehensive information about both the levels and composition of managers' compensation. In the pilot sample, for example, on average top managers received 30 per cent of their total compensation in the form of incentive compensation. At the second level the average was 20 per cent and at the third, 10 per eent. As in the case of the number of organizational levels in a business unit, however, the key issue is not these descriptive data per se but when or if it pays to deviate from these 'normal' levels. Here too the initial research yiclds some interesting results.

Business units generating greater-than-expected profits are characterized by having a high level of incentive pay in the top managers' total compensation package. Interestingly, while incentive compensation is more prevalent in mature markets, the research indicates that the biggest impact is precisely where it is used least-at the beginning and the end of the product life cycle (sec Figure 5).

The impact of incentive compensation at the second level (Figure 6), also shows that the impact of incentive compensation differs by the product life cycle stage. A high level of incentive pay leads to the most substantial benefits in the decline stage at this management level, where such incentives may well be necessary to retain and motivate skilled managers.

\section{Management Characteristics}

There has been a great increase in the flow of corporate exccutives between companies in North America, as attested by the booming revenues of executive search firms. At the same time, many businesses are fighting this trend. They are trying to establish succession systems that will decrease the necd to go outside the organization for management talent in order to minimize disruption and because 


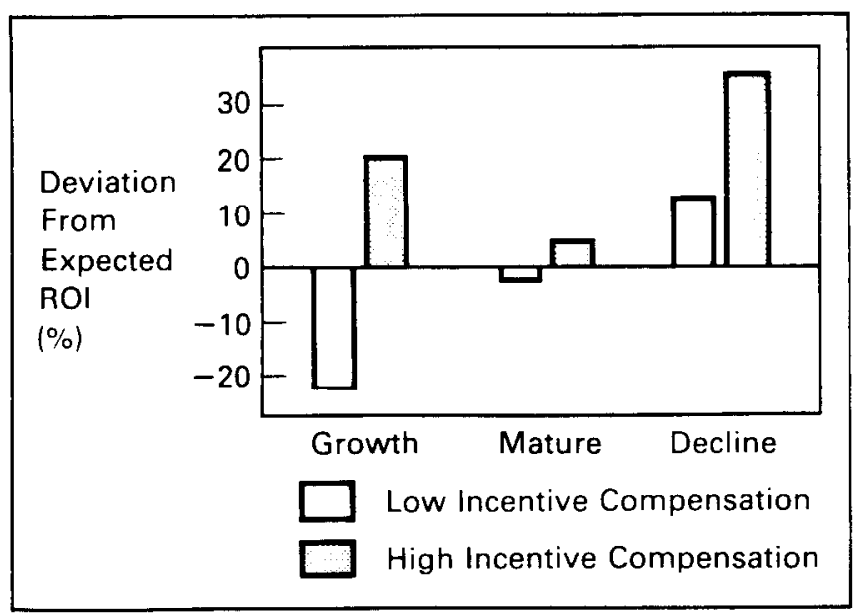

Figure 5. Impact of incentive compensation depends on the product life cycle stage. Top manager's incentive compensation

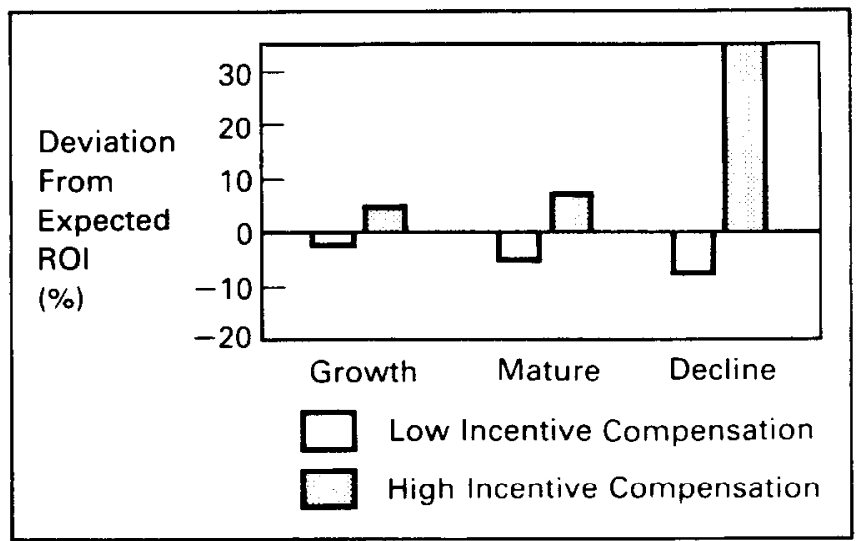

Figure 6. Impact of incentive compensation depends on the product life cycle stage. Sccondlevel manager's incentive compensation

internal development is considered inherently desirable.

The research indicates that the key to the insider versus outsider question is understanding the impact of the business unit's position in the product life cycle. Businesses in the growth stage are more profitable when they draw at least 20 per cent of their managers in the top three levels from outside of the business unit. The new ideas and willingness to consider alternatives to the status quo that can be generated by a higher mix of outsiders are highly adaptive in a turbulent market. For different reasons it is also advantageous to have more outsiders in a declining product life cycle stage. Insiders have a tendency to fail to recognize the onset of decline, and persevere in old strategics and practices that may no longer be effective. Newcomers may be more likely to move away from doing busincss as usual in a declining market. Also, the personnel reductions and cost cutting that are usually required in this stage of the product life cycle are morc difficult for entrenched insiders who have commitments to the existing political order.

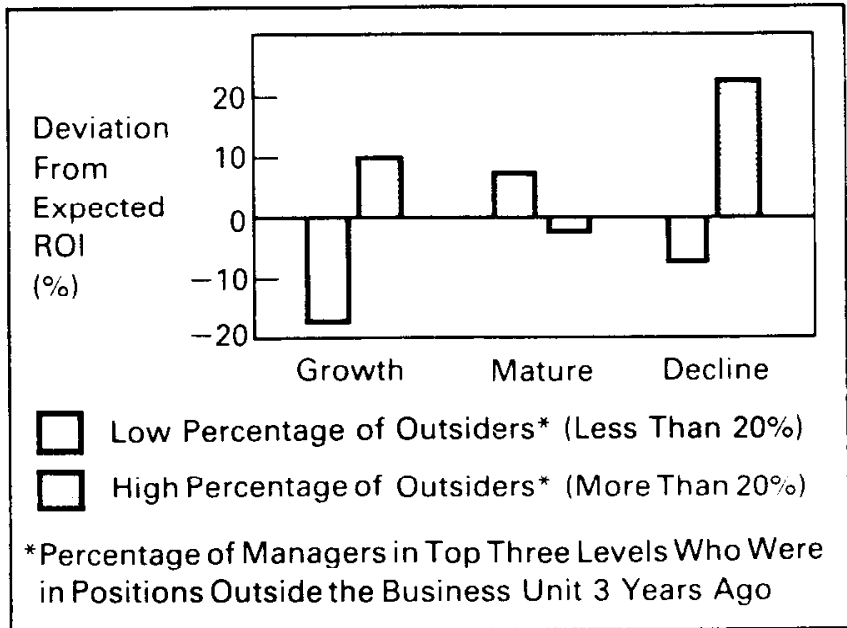

Figure 7. Impact of business unit outsiders depends on product life cycle stage

Only in the mature stage of the product life cycle is it optimal to have less than 20 per cent outsiders. In this stage there is less change in technology, customer needs, and competitor strategy. So business units with high proportions of insiders gain the advantage of greater business-specific knowledgc, while having less need for the innovation that outsiders tend to provide (sce Figure 7).

\section{Organizational Culture}

While organizational culture has had the dubious distinction of being the hot trend of the 1980s, evidence for the connection between culture and business performance has largely consisted of anecdotes and small group studies. The data base provides an empirical link between survey measures of the cultural perceptions of people in the top three levels of management to business unit performance.

There is a substantial association between business unit culture and performance on a number of cultural dimensions. The culture factors range from those that are sometimes considered irrelevant to business performance (c.g. participative style), to those that are more obviously linked to business operations (c.g. adapts to environment). Culture has an effect in both small and large business.

In the survey data, managers were asked not only to indicate whether a given descriptor characterized the present situation, but also to indicate whether or not it should. Data collected in this fashion made possible, among other things, an examination of how a 'culture gap' affects performance, i.c. what occurs if current practices do not mesh with those desired by the business unit's management. Such a 'culture gap' does indecd have a substantial impact on business unit profitability: when the practices of the top management coincide with those desired by their subordinates, performance above expectation is to be observed (sce Figure 8).

\section{OASIS in Practice: A Case Example}

While the fundamental purpose of OASIS is to 


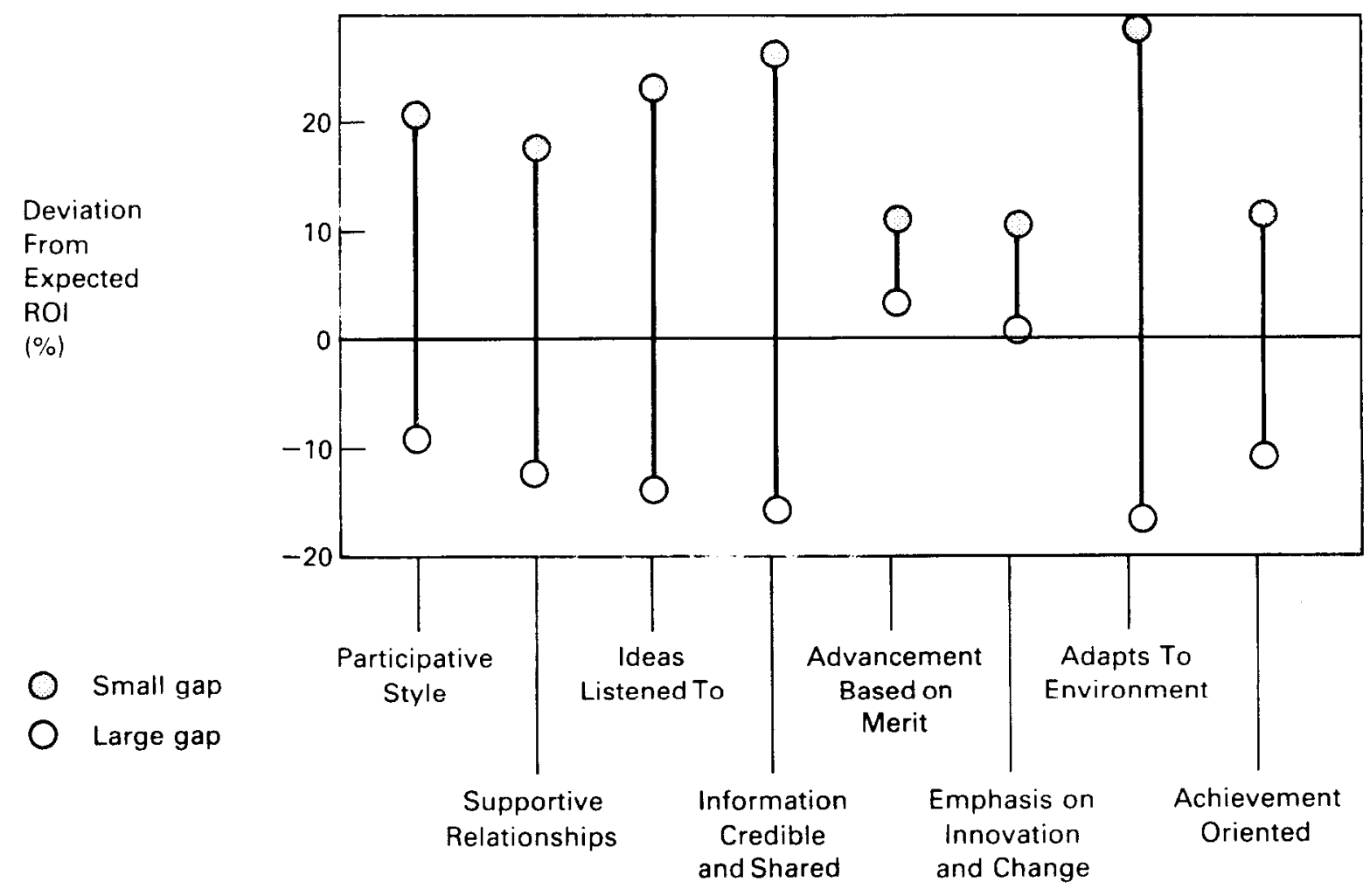

Figure 8 . The gap between desired and current culture affects profitability

determine the relationship between strategy, organization, and performance, the program also provides a tool for practical application. Initial experiences in utilizing OASIS to integrate strategic and organizational analyses in a variety of business units have shown it to be quite useful. The disguised case study described below demonstrates how the model can be applied in practice.

Carling Tools is a highly profitable producer of consumer power tools in North America, commanding a strong number 2 position in the market. Despite this strength, there are signs of trouble. Share is drifting downwards and competitors have been more nimble in introducing new products and special features for existing products.

The management of Carling Tools decided to participate in OASIS because they hoped it would help them find answers to these critical questions:

is Is the basic business secure?

is If not, what needs to be done strategically and tactically?

What organizational changes should be undertaken to support the business strategy?

The OASIS analysis examined the overall strategic position of the busincss, basing its findings on PIMS research results. This analysis highlighted several important facts.
The strategic position of the business was quite strong, with a high expected ROI of 35 per cent. The current performance of the business actually exceeded this strong expectation (actual ROI: 46 per cent). This overperformance, however, did not appear to be due to tight operations (e.g. good control of administrative overheads), but rather because Carling was still leveraging its long history of superior design to maintain premium prices. However, recently Carling had fallen behind its major competitors in terms of innovation and marketing support. An cxamination of similarly structured businesses in the PIMS data base revealed that failure to address this situation would result in the further loss of share and profit margins. However, a number of similar businesses had successfully overcome these weaknesses and even managed to increase share while maintaining margins. The key to their success lay in closing the innovation gap and more effective marketing, both at the trade and consumer level.

This strategic diagnosis set the stage for a review of organizational factors. This process provided considerable guidance on the steps Carling needed to take to implement a strategy or renewcd innovation and marleting vigour.

For example, a comparison with OASIS benchmarks for structural levels showed excess layers of management, particularly in marketing, which 


\section{ORGANIZATIONAL LAYERS ACTUAL EXPECTED}

\begin{tabular}{|c|c|c|}
\hline Operations & 8 & 7 \\
\hline Marketing & 8 & 6 \\
\hline \multirow[t]{2}{*}{ Sales } & 6 & 5 \\
\hline & $\begin{array}{l}\text { Excess Layers of Management } \\
\text { Particularly in Marketing }\end{array}$ & \\
\hline
\end{tabular}

Figure 9. The Carling Tools case-comparison with OASIS benchmarks

would help explain Carling's comparatively sluggish reaction time (see Figure 9).

Furthermore, the business unit itself was too large $(10,000$ employees) for quick response in the market-place. Shielded from direct contact with the market by the over-layered bureaucracy, top managers spent most of their time in financial and administrative activities while devoting little effort to sales and marketing.

The culture of Carling Tools was also a primary contributor to their problems. The OASIS culture survey disclosed an atmosphere which is normally associated with marketing problems: little freedom for independent action; a highly formal environment and little openness to change.

While the review of Carling Tools' organization found a number of strengths, it also indicated that a major change in organization would be required to successfully implement a strategy designed to reverse the recent declines in market share. A number of specific actions were suggested from the study:

is The business should be divided into several smaller, more manageable units that arc morc responsive to the needs of existing and emerging customer segments.

t5 Middle management layers should be removed, increasing senior managers' contact with customers.

is Managers from outside Carling Tools should be recruited into the top levels of the business.

is Incentive compensation should be increased and redesigned to reward growth.

is The General Manager of Carling Tools should initiate a culture change process designed to increase the level of autonomy, informality, and information flow in the top management group.

Top management took a surprisingly positive view of these recommendations, although they dealt with well-established practices in the business. The consultants involved in the case believed that this willingness to change the status quo was due to the link between the strategic and organizational analyses, and because the empirical support for the recommendation enhanced their credibility.

\section{The Next Stage of OASIS}

The initial research results indicate that there are strong relationships berween business strategy, organization and performance. As the data base expands, further research designed to explore more complex questions will be conducted. In recent months a number of companies in Europe have participated in the program. This provides an opportunity to test the initial findings, which were based on data from North American businesses, and to determine the area in which European patterns are different.

We are developing a systcmatic approach to integrating strategy, organization, and performance. While the data base is not large enough to test the complex interrelationships that managers must ultimately master to achicve a sustaincd competitive advantage, the findings are proving to be useful in addressing the problem of strategy implementation.

\section{References}

(1) D. Schendel and C. Hofer(Eds), Strategic Management, Little Brown \& Co., Boston (1979).

(2) See, for example, N. Tichey, Managing Strategic Change, Wiley New York (1983).

(3) See, for example, H. V. Ulrich, Unternehmungspolitik. Paul Haupt, Bern and Stuttgart (1978).

(4) See, for example, H. Mintzberg. The Structure of Organizations, Prentice-Hall, New Jersey.

(5) For a good review of these divergent tendencies see D. Ulrich, $A$ Geller and G. DeSouza, A strategy structure and human resource database: OASIS, Human Resource Management, 23 (1) (1984).

(6) The most widely read texts being those of Michael Porter, Competitive Strategy, The Free Press, New York (1985); and Competitive Advantage. The Free Press, New York (1985)

(7) See, for example, on the subject of organizational design, $H$ Mintzberg, Structure in Fives: Designing Effective Organiza. tions, Prentice-Hall, New Jersey (1983). The classic text on 'culture' is T. Peters and R. Waterman, In Search of Excellence. Harper \& Row, New York (1982).

(8) For a fuller description of the PIMS Program and its underlying philosophy see R. Luchs and R. Müler, Das PIMS Programm Strategien empirisch fundieren, Strategische Planung. 2 (1985).

(9) Many of the basic research findings of the PIMS Program are presented in a recently published book: $R$. Buzzell and $B$. Gale, The PIMS Principles: Linking Strategy to Performance. The Free Press. New York (1987).

(10) R. Hammermesh and R. White, Manage beyond portfolio analysis, Harvard Business Review, January/February (1984). 